${ }^{1}$ Centro de Bioética, Facultad de Medicina, Pontificia Universidad Católica de Chile. ${ }^{2}$ Facultad de Ciencias Biológicas, Pontificia Universidad Católica de Chile.

Fuente de financiamiento: VII Concurso de investigación para académicos. UC 20092010. "Por un auténtico desarrollo del hombre". Pontificia Universidad Católica de Chile.

Vicerrectoría Adjunta de Investigación y Doctorado. Dirección General de Pastoral y Cultura Cristiana. Proyecto N864-47.

Recibido el 18 de julio de 2012, aceptado el $26 \mathrm{de}$ octubre de 2012

Correspondencia a:

Dr. Patricio Ventura-Juncá Alameda 30, Centro de Bioética, Facultad de Medicina, Pontificia Universidad Católica de Chile.

Teléfono: 23543049 E-mail:venturaj@med. puc.cl

\section{Turismo con células madre y requisitos para su uso clínico: desafíos bioéticos más allá del embrión}

\author{
PATRICIO VENTURA-JUNCÁ ${ }^{1}$, ALEJANDRO ERICES ${ }^{2}$, MANUEL J. SANTOS²
}

\section{Bioethical challenges of stem cell tourism}

Stem cells have drawn extraordinary attention from scientists and the general public due to their potential to generate effective therapies for incurable diseases. At the same time, the production of embryonic stem cells involves a serious ethical issue concerning the destruction of human embryos. Although adult stem cells and induced pluripotential cells do not pose this ethical objection, there are other bioethical challenges common to all types of stem cells related particularly to the clinical use of stem cells. Their clinical use should be based on clinical trials, and in special situations, medical innovation, both of which have particular ethical dimensions. The media has raised unfounded expectations in patients and the public about the real clinical benefits of stem cells. At the same time, the number of unregulated clinics is increasing around the world, making direct offers through Internet of unproven stem cell therapies that attract desperate patients that have not found solutions in standard medicine. This is what is called stem cells tourism. This article reviews this situation, its consequences and the need for international cooperation to establish effective regulations to prevent the exploitation of patients and to endanger the prestige of legitimate stem cell research.

(Rev Med Chile 2013; 141: 1034-1040).

Key words: Ethics, medical; Cord blood stem cells transplantation; Stem cells.
E n la medicina del siglo 21 existe la esperanza de que el avance en la investigación y uso clínico de la células madre (CM) produzca un progreso extraordinario en el tratamiento de enfermedades incurables o en que éste es complejo e insuficiente. El trasplante con CM pretende resolver la patología involucrada mediante la regeneraciónde los tejidos dañados. Enfermedades neurodegenerativas como el Alzheimer (EA), el Parkinson (EP) y la esclerosis lateral amiotrófica (ELA) y otras como la diabetes, cáncer, infarto cardíaco y enfermedades inmunológicas están en la primera línea de ésta expectativa ${ }^{1}$.

Existen varios tipos de CM, todas caracterizadas por su capacidad de auto regeneración, potencial de diferenciación y de regenerar tejidos ${ }^{1}$. Se diferencian por su origen y el diverso grado que tienen en las características mencionadas.

\section{Células madre embrionarias (pluripotentes) ${ }^{1}$ (CME)}

Fueron descubiertas en 1981 por Evansy Martin que, lograron aislar y cultivar in vitro las células pluripotenciales del macizo celular interno del blastocisto de ratón ${ }^{2,3}$. Significó un hito histórico para la comprensión del desarrollo de la homeostasis tisular y de la medicina regenerativa (MR). Se distinguen por su capacidad de autoreplicarse indefinidamente manteniendo su carácter pluripotencial pudiéndose diferenciar en las tres capas embrionarias de las cuales se desarrollan todos los tejidos del organismo. Su capacidad regenerativa ha sido probada en estudios preclínicos in vitro y en animales. El traspaso a estudios clínicos no ha podido concretarse por problemas de seguridad no resueltos como es el caso de producción de tumores. A esto se agrega la grave objeción ética 
de que su producción implica la destrucción de embriones humanos. Hay 6 ensayos clínicos para el tratamiento de enfermedades del ojo ${ }^{4}$.

\section{Células madre adultas (multipotentes) ${ }^{1}$ (CMA)}

Estas se encuentran en diversos tejidos del organismo ya constituido y son capaces de regenerar linajes celulares del tejido del cual provienen. El caso más típico y estudiado es de las CMA hematopoyéticas y mesenquimáticas. También se encuentran en la sangre del cordón umbilical y en el cordón mismo ${ }^{5}$.

El primer trasplante de médula ósea con CM hematopoyéticas realizado en 1957 por E. D. Thomas para el tratamiento de una leucemia abrió una nueva forma de regenerar tejidos ${ }^{6}$.

El cultivo y auto renovación in vitro de las CMA es difícil. Se ha logrado su transdiferenciación a células de otros tejidos abriendo un campo más amplio para las CMA en la medicina regenerati$\mathrm{va}^{7}$. Al año 2012, los ensayos clínicos superan los $1.000^{4}$

\section{Células madre inducidas (iPS) (sigla inglesa)}

El año 2006 Takahashi y Yamanaka reprogramaron fibroblastos adultos de ratón al estado pluripotencial introduciendo cuatro factores de transcripción $^{8}$. Las iPS tienen características y comportamiento casi idénticos a las CME. Este descubrimiento señero abrió un nuevo y amplio camino para la investigación con CM y la medicina regenerativa y le mereció a Yamanaka el premio Nobel 2012. Se ha logrado obtener iPS a partir de células diferenciadas humanas de diversos tejidos 9 . Quedan aspectos complejos que resolver, como asegurarse que la reprogramación al estado pluripotencial sea completa y estable, antes de pasar a uso clínico ${ }^{10}$. Esta técnica evita el problema del rechazo al ser obtenidas del propio paciente y soslaya el principal problema ético de las CME pues no requiere el uso de embriones humanos.

Se ha logrado la reprogramación directa de fibroblastos a células de tejidos específicos, como cardiomiocitos y hepatocitos ${ }^{11,12}$. Con esto se sortea el paso por el estado pluripotencial con lo que se evitaría la producción de tumores ${ }^{11}$.

\section{El debate bioético}

Este ha estado centrado fundamentalmente en el problema de la destrucción de embriones humanos para la obtención de CME. La biología ha demostrado que un nuevo organismo humano comienza con la fecundación. Por eso, el debate es más filosófico que científico, pues se refiere a si el ser humano en esta etapa de desarrollo es moralmente relevante y posee el derecho a la inviolabilidad de su vida como en etapas posteriores ${ }^{13}$.

Hoy, emergen nuevos problemas éticos relevantes comunes a todas la CM relacionados especialmente con el traspaso de los estudios preclínicos a la clínica ${ }^{14}$. A los requisitos estándares para cualquier investigación clínica, en el caso de las CM se agregan requerimientos particulares ${ }^{15}$. A diferencia de un fármaco, las CM trasplantadas permanecen en el organismo y su comportamiento es todavía en muchos aspectos impredecible. El tipo de CM, su origen, producción y almacenamiento deben ser claramente explicitados en el consentimiento informado. Otros temas éticos emergentes incluyen el uso de niños como donantes, la propiedad intelectual y de las patentes, el acceso equitativo a los tratamientos y el almacenamiento de sangre de cordón en bancos privados ${ }^{16-18}$.

Finalmente, un problema de importancia creciente es el ofrecimiento de tratamientos con CM no probados en instituciones no reguladas. Es lo que se ha denominado turismo con $\mathrm{CM}$ que es el foco de este artículo.

\section{Expectativas fundadas y esperanzas irreales}

El descubrimiento de las CME produjo en el público grandes expectativas de su eventual capacidad curativa. Como lo expresa Stephenson: "Los medios han incentivado la creencia de que las CME poseen virtualmente un poder ilimitado de reparación y que representan un remedio universal para casi todas las enfermedades" ${ }^{19}$.Con frecuencia entrevistas a científicos y la información que proveen los medios de comunicación, son interpretados por el público y los pacientes como si los tratamientos con CM estuvieran a un paso de ser utilizados ${ }^{20}$.

La International Society for Stem Cell Research (ISSCR) ha precisado que las únicas terapias con $\mathrm{CM}$ incorporadas como tratamientos estándar, solo existen con CMA para unas pocas enfermedades $^{21}$. Es el caso del trasplante de células madre hematopoyéticas para la leucemia y otras enferme- 
dades de la sangre y más recientemente el uso de $\mathrm{CM}$ epiteliales para el tratamiento de quemaduras y de algunos problemas de la córnea ${ }^{22}$. El largo camino desde la investigación preclínica con CM al traspaso clínico es difícil de ser comprendido por el público.

\section{Ensayos clínicos, innovación médica. Ética de la investigación y del cuidado del enfermo}

La experiencia ha demostrado que la ruta más segura y responsable para la aprobación de nuevos tratamientos es la de los ensayos clínicos (EC). Estos tienen una secuencia que va desde la investigación preclínica a los estudios clínicos fase I-II-III y IV, para certificar su seguridad y beneficio. Este proceso que integra aspectos éticos y científicos ha significado un sólido avance en la medicina y la protección de los pacientes, constituyéndose en el paradigma de la investigación clínica ${ }^{23}$.

Pero es un hecho que el progreso médico en diversas áreas de la medicina se ha realizado también con tratamientos innovadores que no siguen el modelo de los EC. El caso más clásico es el de la cirugía ${ }^{24}$.

Los EC y la innovación médica tienen una finalidad diferente y por ende requisitos éticos particulares. El objetivo de los EC es producir un conocimiento generalizable que permita el uso de nuevos tratamientos con efectividad y seguridad. El de los tratamientos innovadores es primariamente el bien del paciente en particular. El primero es terreno de la ética de la investigación, el segundo, el de la ética del cuidado del paciente ${ }^{25,26}$. Si bien, en ambos casos debe haber una evaluación de beneficios versus riesgos, existir experiencia preclínica y coherencia científica, la aplicación de los principios éticos debe ser concordante con el fin perseguido. Esto incide en el tipo de consentimiento informado y la forma como los protocolos son revisados por pares expertos. Quienes participan en una investigación deben saber que el objetivo primario no es el tratamiento particular de su enfermedad y comprender bien los riesgos que esta conlleva. En el tratamiento innovador el enfermo debe saber claramente los riesgos que conlleva un tratamiento no comprobado ${ }^{27}$.

El tema de tratamientos innovadores con CM, es objeto de especial interés y controversia ${ }^{25,28}$.

\section{El turismo con células madre}

Las grandes expectativas despertadas por las $\mathrm{CM}$ ha producido dos hechos que se interrelacionan. Por un lado, pacientes angustiados con enfermedades graves, en que la medicina convencional es ineficaz o no existe, buscan ilusionados tratamientos con CM. Simultáneamente en las últimas décadas surge con frecuencia creciente, clínicas no reguladas que ofrecen tratamientos con $\mathrm{CM}$ atrayendo a estos enfermos. Son miles los que viajan y gastan grandes cantidades de dinero para acudir a ellas ${ }^{29}$. Esto se presta para crear ilusiones, riesgos impredecibles, desinformación y explotación económica. Es el llamado "turismo con células madre". Estos se publicitan a través de la web con lo que llegan directamente a un amplio número de pacientes y evitan el control gubernamental ${ }^{30}$. Esto debe diferenciarse del ofrecimiento legítimo de nuevas opciones terapéuticas que brindan centros calificados en diversas partes del mundo.

En el año 2006 un artículo de la revista Science advertía la existencia de 9 instituciones en diversas partes del mundo que ofrecían tratamientos con CM para un amplio espectro de enfermedades ${ }^{31}$. En la mayoría eran de tipo neurológico (Parkinson, esclerosis lateral amiotrófica, lesiones de la médula espinal, autismo, depresión) pero la variedad incluía infarto del miocardio, diabetes, SIDA, cáncer e impotencia. Las CM utilizadas eran mayoritariamente CMA del propio paciente, del cordón umbilical o procedente de abortos (fetales). El costo de los tratamientos era de alrededor de los US 20.000 sin considerar los gastos de viajes y alojamiento. En otro estudio, Lau y col. estudiaron los ofrecimientos de tratamientos con $\mathrm{CM}$ por Internet de 19 clínicas, la forma como éstos eran presentados y la evidencia clínica existente para justificarlos ${ }^{32}$. Los tratamientos eran muy variados y presentados en forma optimista. No había información precisa del tipo de CM utilizada, de su origen, forma de administración, ni si los protocolos fueron evaluados por expertos. Tampoco había una clara mención de los riesgos. Todas las clínicas comunicaban casos de mejoría, a veces espectaculares, sin apoyo estadístico que evaluara los resultados. Concluyen que la información que reciben los pacientes por Internet es incompleta y que puede aumentar las expectativas del público sin fundamentos sólidos. Otro estudio que contactó 23 proveedores de tratamientos con 
CM llegó a conclusiones semejantes, advirtiendo un porcentaje importante de menores entre los tratados ${ }^{33}$.

El número de estas clínicas va en aumento,se calcula que hoy existen más de 700, la mayoría en países en desarrollo como Argentina, Costa Rica, Tailandia o con pocas regulaciones como Rusia y China, pero excepcionalmente también en países con mayor resguardo como Holanda y Alemania $^{34-36}$. En China se calcula que hasta el año 2009 se trataron alrededor de 6.500 pacientes en dos de las clínicas más grandes, muchos venidos de otros países $^{37}$. En Rusia e India se da una situación aná$\operatorname{loga}{ }^{27}$. Los medios de comunicación hacen de caja de resonancia al comentar las ofertas y resultados de manera muchas veces optimista, influyendo en la percepción de los pacientes ${ }^{38}$.

La publicación de problemas por este tipo de tratamientos con CM corrobora los riesgos que tienen para los pacientes, para el prestigio de la investigación y buen uso clínico de las CM. Se ha comunicado la presencia de un tumor cerebral en un paciente al que se le inyectaron CM neurales fetales en el líquido cefalorraquídeo en Rusia ${ }^{39}$. En Tailandia la inyección en el riñón de CMA autólogas produjo una forma especial de tumor en un niño ${ }^{40}$. En Corea se estudia la muerte de dos personas que recibieron tratamientos con $\mathrm{CM}$, y en Alemania la muerte de un niño con parálisis cerebral al cual se le inyectaron CM en el cerebro ${ }^{41,42}$.

\section{La urgencia de establecer regulaciones. El eventual conflicto con la autonomía del paciente}

Científicos y bioeticistas han señalado con fuerza la necesidad de establecer criterios de regulación dado los graves problemas científicos y éticos que subyacen en esta situación ${ }^{43}$.

La ISSCR ha establecido orientaciones respecto a los requerimientos éticos y científicos tanto para los ensayos clínicos como para los tratamientos innovadores ${ }^{21}$. En ambos casos debe existir suficiente experiencia preclínica, coherencia científica, comparación con otros tratamientos vigentes (si es que los hay). Especial importancia se debe dar al proceso de consentimiento informado. Este debe incluir el tipo y origen de las CM y sus riesgos específicos, informar claramente la posibilidad de comportamientos adversos no esperados y el desconocimiento de efectos a largo plazo. Los par- ticipantes deben comprender en forma ecuánime los posibles beneficios terapéuticos y la existencia de tratamientos alternativos. Clave es la revisión por pares calificados en el ámbito científico y ético de los protocolos de investigación de los ensayos clínicos y del protocolo de un tratamiento innovador. La ISSCR considera que los tratamientos innovadores se deben dejar para un grupo especial de pacientes graves e intratables por la medicina convencional. Debe evaluarse que el paciente haya comprendido que es una intervención no probada y de los posibles riesgos y beneficios, que haya una aprobación escrita por revisores competentes, seguimiento de los pacientes, evaluación sistemática de los resultados y el propósito de moverse a ensayos clínicos en un tiempo adecuado.

La línea divisoria entre tratamientos innovadores y turismo en $\mathrm{CM}$ no es siempre fácil de establecer ${ }^{26}$. Aquí se ha generado una discusión entre la International Cellular Medicine Society (ICMS), sociedad formada por científicos, médicos y pacientes y la ISSCR. La ICMS considera que las orientaciones de la ISSCR están más dirigidas a la investigación y que impiden la debida autonomía de los pacientes ${ }^{44}$. Hay pacientes cuyo interés primario no es expandir el conocimiento sino que mejorarse y sobrevivir. Esperar los resultados de estudios aleatorios que pueden demorar años resulta para ellos una opción ajena a sus necesidades que son con frecuencia urgentes y vitales. Independiente de esta disputa hay que reafirmar que aumentan los ofrecimientos inaceptables que se prestan para que los pacientes puedan ser engañados ${ }^{45}$. Para evitar esto, la ISSCR publicó en Internet el Manual del Paciente sobre Terapias con $\mathrm{CM}$, en varios idiomas, para orientar a pacientes y médicos ${ }^{46}$. A esto agregó la posibilidad de ser consultada por la calidad de alguna clínica en particular, pero esto fue suspendido debido a amenazas legales ${ }^{47}$. En países emergentes se ha abordado el tema de la necesidad de regulaciones $y$ las insuficiencias existente ${ }^{48}$.

Por último, hay que considerar que en diversas ocasiones hay médicos que usan fármacos que están en fase experimental o que son usados para tratamientos para los cuales no fueron aproba$\operatorname{dos}^{49}$. Se discute la licitud de usar CM aprobadas para una determinada finalidad en el tratamiento de una enfermedad para la cual no están específicamente aprobadas. Esto ha suscitado la intervención de la Food and Drug Administration (FDA) 
por el uso de CM que han hecho algunas clínicas en Estados Unidos de Norteamérica ${ }^{50}$.

\section{Situación en Chile}

En Chile hay investigación preclínica y publicaciones en CM, especialmente revisiones ${ }^{51,52,53}$. Existen centros universitarios y hospitalarios que con financiamiento estatal han puesto en marcha estudios clínicos. Hay estudios iniciales para patologías neurológicas y reumatológicas ${ }^{54,55}$. Los investigadores advierten que se debe tener gran cautela y rigurosidad en estos intentos ${ }^{55}$.

Los primeros trasplantes de médula se efectuaron en los años 1988-8956. Luego, éste se ha convertido en un tratamiento estándar para la leucemia y otras enfermedades de la sangre en el área pública y privada ${ }^{57}$. Pero en la prensa con frecuencia aparece información sobre las perspectivas de tratamientos con CM que no se condicen con el estado de avance para su uso clínico y que despiertan ilusiones en los pacientes.

Está también el debate sobre los bancos públicos y privados de CM de cordón. La información publicitada en Internet por alguno de ellos despierta a veces en los padres expectativas que no son coherentes con lo recomendado por la literatura científica $^{18}$.

En Chile se debe implementar la Comisión Nacional de Bioética prevista en la ley 20.120 para cautelar la legitimidad científica y ética del uso de CM.

\section{Conclusiones}

Los aspectos éticos de la investigación y aplicación clínica de las $\mathrm{CM}$ necesariamente van unidos a los descubrimientos y progresos científicos. En un comienzo el gran debate ético fue en relación al estatus moral del embrión humano. Si bien este permanece como elemento esencial, nuevos desarrollos científicos y en especial el camino hacia la aplicación clínica, de las CM han traído al primer plano otros desafíos éticos. La esperanza de curación de diversas enfermedades ha producido una efervescencia desproporcionada en el público que no se condice con el estado actual del uso clínico de las CM. La aparición de clínicas sin regulación que ofrecen tratamientos con CM, en su mayoría, con graves falencias científicas y éticas, atraen a cientos de pacientes que no encontrando solución en la medicina estándar acuden a ellas con grandes expectativas y desembolso de recursos. Esto se ha llamado turismo con CM. Sorprendentemente, un estudio mostró que muchas personas sanas considerarían acudir a estas clínicas si se encontrarán en situaciones semejantes ${ }^{58}$. La comunidad científica y los bioeticistas han reaccionado a esta situación proporcionando orientaciones para el paso lícito de la investigación preclínica a la clínica precisando los criterios éticos y científicos para los ensayos clínicos y las situaciones excepcionales que validarían la realización de tratamientos innovadores fuera de los EC. Es probable que en la medida que haya mayor aprobación del uso de CM por los organismos competentes los ofrecimientos por clínicas no reguladas aumenten al igual que el interés de los pacientes por ellas en un mundo globalizado en que la información está cada vez más al alcance de todos. Y, que sea más compleja la distinción entre turismo médico con $\mathrm{CM}$ e innovación clínica aceptable de acuerdo a parámetros precisos. Para responder a este desafío se requiere que se establezcan orientaciones y regulaciones globalizadas que implique un acuerdo entre los países $^{22,59}$, y que los médicos asuman su responsabilidad ética y científica frente a los pacientes que les soliciten asesoría sobre esto tratamientos ${ }^{60}$. Con esto se podrá proteger efectivamente a los pacientes y garantizar el buen uso del progreso sorprendente al que se espera que se llegue con los tratamientos e investigación con CM, para el progreso de la ciencia y el bien de los pacientes considerando los requerimientos de la justicia social a nivel mundial.

\section{Referencias}

1. NIH disponible enhttp://stemcells.nih.gov/info/basics/ defaultpage.asp (consultado el 2 de octubre de 2012).

2. Evans MJ, Kaufman MH. Establishment in Culture of Pluripotential Cells from Mouse Embryos. Nature 1981; 292: 54-156.

3. Martin GR. Isolation of a Pluripotent Cell Line from Early Mouse Embryos Cultured in Medium Conditioned by Teratocarcinoma Stem Cells. Proc Natl Acad Sci U S A 1981; 78 (12): 7634-8.

4. Disponible en: http://clinicaltrials.gov/ct (consultado el 4 de octubre de 2012) 
5. Carvalho MM, Teixeira FG, Reis RL, Sousa N, Salgado AJ. Mesenchymal stem cells in the umbilical cord: phenotypic characterization, secretome and applications in central nervous system regenerative medicine. Curr Stem Cell Res Ther 2011; 6 (3): 221-8.

6. Thomas ED, Lochte HL Jr, Lu WC, Ferrebee JW. Intravenous infusion of bone marrow in patients receiving radiation and chemotherapy. N EnglJ Med 1957; 257: 491-6.

7. Ding Z, Burghoff S, Buchheiser A, Kögler G, Schrader J. Survival, integration and differentiation of unrestricted somatic stem cells (USSCs) in the heart. Cell Transplant 2012; [Epub ahead of print] (Consultado el 4 de octubre de 2012).

8. Takahashi K, Yamanaka S. Induction of pluripotent stem cells from mouse embryonic and adult fibroblast cultures by defined factors. Cell 2006; 126 (4): 663-76.

9. Yu J, Vodyanik MA, Smuga-Otto K, Antosiewicz-Bourget J, Frane JL, Tian S, et al. Induced pluripotent stem cell lines derived from human somatic cells. Science 2007; 318 (5858): 1917-20.

10. Hanna JH, Saha K, Jaenisch R. Pluripotency and cellular reprogramming: facts, hypotheses, unresolved issues. Cell 2010; 143 (4): 508-25.

11. Margariti A, Winkler B, Karamariti E, Zampetaki A, Tsai TN, Baban D, et al. Direct reprogramming of fibroblasts into endothelial cells capable of angiogenesis and reendothelialization in tissue-engineered vessels.Proc Natl Acad Sci USA 2012; 109 (34): 13793-8.

12. Huang P, He Z, Ji S, Sun H, Xiang D, Liu C, et al. Induction of functional hepatocyte-like cells from mouse fibroblasts by defined factors. Nature 2011; 475 (7356): 386-9

13. Ventura-Juncá P, Santos MJ. The beginning of life of a new human being from the scientific biological perspective and its bioethical implications. Biol Res 2011; 44 (2): 201-7.

14. Lo B, Parham L. Ethical issues in stem cell research. Endocr Rev 2009; 30 (3): 204-13.

15. Lo B, Kriegstein A, Grady D.Clinical trials in stem cell transplantation: guidelines for scientific and ethical review.Clin Trials 2008; 5 (5): 517-22.

16. American Academy of Pediatrics Committee on Bioethics. Children as hematopoietic stem cell donors. Pediatrics 2010; 214: 392-404.

17. Bahadur G, Morrison M. Patenting human pluripotent cells: balancing commercial, academic and ethical interests. Hum Reprod 2010; 25 (1): 14-21.

18. Smith FO. Why do parents engage in private cord blood banking: Fear, realistic hope or a sense of control? Pediatr Blood Cancer 2011; 56 (7): 1003-4.
19. Stephenson E, Ogilvie CM, Patel H, Cornwell G, Jacquet L, Kadeva N, et al. Safety paradigm: genetic evaluation of therapeutic grade human embryonic stem cells. J R Soc Interface 2010; 7 Suppl 6: S677-88.

20. Devereaux M, Loring JF. Growth of an industry: how U.S. scientists and clinicians have enabled stem cell tourism. Am J Bioeth 2010; 10 (5): 45-6.

21. Hyun I, Lindvall O, Ahrlund-Richter L, Cattaneo E, Cavazzana-Calvo M, Cossu G, et al. New ISSCR guidelines underscore major principles for responsible translational stem cell research. Cell Stem Cell 2008; 3 (6): 607-9.

22. Rama P, Matuska S, Paganoni G, Spinelli A, De Luca M, Pellegrini G. Limbal Stem-Cell Therapy and Long-Term Corneal Regeneration. N Engl J Med 2010; 363: 147-55.

23. Meadows M. Promoting safe and effective drugs for 100 years. FDA Consum 2006; 40 (1): 14-20.

24. Agich GJ. Ethics and innovation in medicine. J Med Ethics 2001; 27 (5): 295-6.

25. Hyun I. Allowing innovative stem cell-based therapies outside of clinical trials: ethical and policy challenges. J Law Med Ethics 2010; 38 (2): 277-85.

26. Lindvall $\mathrm{O}$, Hyun I. Medical innovation versus stem cell tourism. Science 2009; 324(5935): 1664-5.

27. Cohen $\mathrm{CB}$, Cohen PJ. International stem cell tourism and the need for effective regulation. Part I: Stem cell tourism in Russia and India: clinical research, innovative treatment, or unproven hype? Kennedy Inst Ethics J 2010; 20 (1): 27-49.

28. McMahon DS, Thorsteinsdóttir H, Singer PA, Daar AS. Cultivating regenerative medicine innovation in China. Regen Med 2010; 5 (1): 35-44

29. Kiatpongsan S, Sipp D. Medicine. Monitoring and regulating offshore stem cell clinics. Science 2009; 323 (5921): 1564-5.

30. Taylor PL, Barker RA, Blume KG, Cattaneo E. Patients beware: commercialized stem cell treatments on the web. Cell Stem Cell 2010; 7 (1): 43-9.

31. Enserink M. Biomedicine.Selling the stem cell dream. Science 2006; 313 (5784): 160-3.

32. Lau D, Ogbogu U, Taylor B, Stafinski T, Menon D, Caulfield T. Stem cell clinics online: the direct-to-consumer portrayal of stem cell medicine. Cell Stem Cell 2008; 3 (6): 591-4.

33. Regenberg AC, Hutchinson LA, Schanker B, Mathews DJ. Medicine on the fringe: stem cell-based interventions in advance of evidence. Stem Cells 2009; 27 (9): 2312-9.

34. Ryan KA, Sanders AN, Wang DD, Levine AD. Tracking the rise of stem cell tourism. Regen Med 2010; 5 (1): 27 33.

35. Sheldon T. Holland Bans Private Stem Cell Therapy. BMJ 
Turismo con células madre - P. Ventura-Juncá et al

2007; 334 (7583): 12.

36. Stafford N. Germany tightens law on stem cell treatments. BMJ 2009; 339: b2967.

37. McMahon D, Thorsteinsdóttir H. Lost in translation: China's struggle to develop appropriate stem cell regulations. Scripted 2010; (2): 283-94. Disponible en http:// www.law.ed.ac.uk/ahrc/script-ed/vol7-2/mcmahon.asp. (Consultado el 4 de julio de 2012).

38. Zarzeczny A, Rachul C, Nisbet M, Caulfield T. Stem cell clinics in the news. Nat Biotechnol 2010; 28 (12): 1243-6.

39. Amariglio N, Hirshberg A, Scheithauer BW, Cohen Y, Loewenthal R, Trakhtenbrot L, et al. Donor-derived brain tumor following neural stem cell transplantation in an ataxia telangiectasia patient. PLoS Med 2009;6(2):e1000029. Disponible en: http://www.plosmedicine.org/article/info\%3Adoi\%2F10.1371\%2Fjournal. pmed.1000029. (Consultado el 4 de julio de 2012).

40. Thirabanjasak D, Tantiwongse K, Thorner PS. Angiomyeloproliferative lesions following autologous stem cell therapy. J Am SocNephrol 2010; 21 (7): 1218-22.

41. Cyranoski D. Korean deaths spark inquiry. Nature 2010; 468 (7323): 485.

42. Tuffs A. Stem cell treatment in Germany is under scrutiny after child's death. BMJ 2010; 341: c6203.

43. Gunter KC, Caplan AL, Mason C, Salzman R, Janssen WE, Nichols K, et al. Cell therapy medical tourism: time for action. Cytotherapy 2010; 12 (8): 965-8.

44. Dolginn E. Survey details stem cell clinics ahead of regulatory approval. Nature 2010; 16 (5): 495.

45. Caulfield T. Should we call it fraud? Hastings Cent Rep 2012; 42 (1): 49.

46. ISSCR Disponible en: http://www.isscr.org/clinical_ trans/patient_handbook.html. (Consultado el 9 marzo de 2012).

47. Ledford H. Stem-cell scientists grapple with clinics. Nature 2011; 474 (7353): 550.

48. George B. Regulations and guidelines governing stem cell based products: Clinical considerations. PerspectClin Res 2011; 2 (3): 94-9.

49. Radley DC, Finkelstein SN, Stafford RS. Off-label pres- cribing among office-based physicians. Arch Intern Med 2006; 166 (9): 1021-6.

50. Lysaght T, Campbell AV. Regulating autologous adult stem cells: the FDA steps up. Cell Stem Cell 2011; 9 (5): 393-6.

51. Minguell JJ, Florenzano FM, Ramírez MR, Martínez RF, Lasala GP. Intracoronary infusion of a combination of bone marrow-derived stem cells in dogs. Exp Clin Cardiol 2010; 15 (2): 17-20.

52. Ezquer F, Ezquer M, Simon V, Conget P. The antidiabetic effect of MSCs is not impaired by insulin prophylaxis and is not improved by a second dose of cells. PLoS One 2011; 6 (1): e16566. Disponible en: http://www. plosone.org/article/info\%3Adoi\%2F10.1371\%2Fjournal. pone.0016566. (Consultado el 4 de julio de 2012).

53. Minguel JJ, Erices A. Mesenchymal stem cells and the treatment of cardiac disease. Exp Biol Med (Maywood). 2006; 231 (1): 39-49.

54. Soler B, Fadic R, von Bernhardi R Stem cells therapy in amyotrophic lateral sclerosis treatment. A critical view]. Rev Neurol 201; 52 (7): 426-34.

55. Norambuena GA, Khoury M, Jorgensen C. Mesenchymal stem cells in osteoarticular pediatric diseases: an update. Pediatr Res 2012; 71: 452-8.

56. Del Favero A, Fifueroa H, Monsalve V, Zúñiga C, Madrid J, Braun SD, et al. Trasplante de médula ósea alogénica: Comunicación de tres casos efectuados en Chile. Rev Med Chile 1989; 117: 174-8.

57. Barriga F, Bertín P, Baeza R, Pereira J, Schwartzmann L, Oliva J, et al. Allogenic bone marrow transplantation in the treatment of malignant hematologic disease. Rev Med Chile 1995; 123 (5): 605-11.

58. Einsiedel EF, Adamson H. Stem cell tourism and future stem cell tourists: policy and ethical implications. Dev World Bioeth 2012; 12 (1): 35-44.

59. Shalev C. Stem cell tourism a challenge for trans-national governance. Am J Bioeth 2010; 10 (5): 40-2.

60. Levine AD, Wolf LE. The roles and responsibilities of physicians in patients' decisions about unproven stem cell therapies J Law Med Ethics 2012; 40 (1): 122-34. 